\title{
Simultaneous action of surfactant modified sugarcane bagasse: Adsorbent and antibacterial agent
}

\author{
Nik Ahmad Nizam Nik Malek*, Muhammad Hafizuddin Yusof, Auni Afiqah Kamaru \\ ${ }^{a}$ Faculty of Biosciences and Medical Engineering, Universiti Teknologi Malaysia, 81310 Skudai, Johor, Malaysia \\ *Corresponding author: niknizam@utm.my
}

\section{Article history}

Received 5 May 2018

Revised 1 June 2018

Accepted 19 July 2018

Published Online 4 February 2019

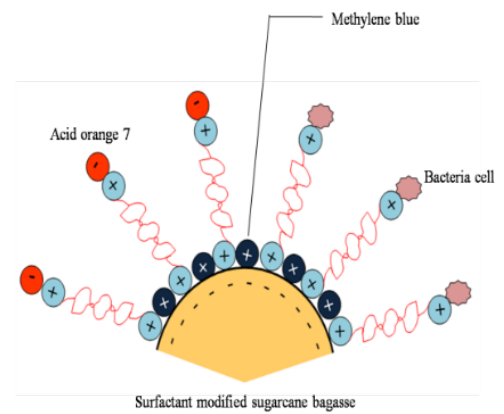

\begin{abstract}
Simultaneous action of surfactant modified sugarcane bagasse (SBH) for dye adsorption and antibacterial activity were investigated. SBH was subjected for adsorption of cationic dye, methylene blue (MB) and anionic dye, methyl orange (MO). Antibacterial activity of SBH was tested against gram negative bacterium (Escherichia coli ATCC11229) and gram positive bacteria (Enterococcus faecalis ATCC 29212 and Staphylococcus aureus ATCC6538). SBH was prepared by reacting sugarcane bagasse (SB) with different concentrations of cationic surfactant, hexadecyltrimethylammonium bromide HDTMA-Br) $(0.1,1.0$ and $4.0 \mathrm{mM})$. The adsorbed amount of HDTMA-Br onto SBH was determined after modification process. SB and SBH were structurally characterized by FTIR spectroscopy. Results from simultaneous action study demonstrated that SB showed adsorption affinity towards $M B$ and $M O$ while the antibacterial activity of SB increased after the surfactant modification reaction. SB modified with $4.0 \mathrm{mM}$ of HDTMA-Br (SBH4.0) exhibited the highest adsorption capacity and antibacterial activity. SBH demonstrated excellent antibacterial activity against gram negative in comparison to gram positive bacteria. In conclusion, the modification of SB with high concentration of HDTMA-Br enhanced the simultaneous action of cationic and anionic dye adsorption and the antibacterial activity against gram negative bacteria.
\end{abstract}

Keywords: Sugarcane bagasse, adsorption, dye, antibacterial activity

\section{INTRODUCTION}

Water pollution due to urbanization and industrialization is a serious environmental problem that experienced by society nowadays. The direct discharge of industrial effluent containing dyes exerts negative effects towards natural ecosystem due to non-biodegradable and toxic properties of dye [1]. Recently, enormous/massive attention has been focused on preparing adsorbent from diverse organic and inorganic materials. However, several important factors such as low capital cost, availability of selected material and high adsorption capacity need to be taken into consideration while choosing the suitable adsorbent for removal of different types of dye in aqueous solution. Sugarcane bagasse is reported as primary and massive agro industrial waste being produced by agricultural industry in Malaysia [2]. Malaysia's sugar industry requires approximately 146, 164 metric tons of sugarcane for production of refined sugar in 2012 [2]. In general, a tonne of sugarcane generates $280 \mathrm{~kg}$ of bagasse, the fibrous waste that remained after sugar extraction from sugarcane [3]. Although the by-products from sugarcane bagasse farming activity exhibit no commercial value for environmental and economical purposes [4], sugarcane bagasse can be a potential material as an effective adsorbent for removal of dye from aqueous solution [5].
The presence of nitrogen, phosphorus and carbon in wastewater from industrial effluent promote the emergence of unwanted microorganisms. These elements provide the necessary basic nutrients for continuous growth of different types of bacteria [6]. Therefore, simultaneous adsorbent and antibacterial agent is required in order to eliminate environmental pollution and bacterial growth problems. Hence, in this study, modification of sugarcane bagasse using cationic surfactant, hexadecyltrimethylammonium bromide (HDTMA-Br) was applied for simultaneous action on dye adsorption and antibacterial activity. Two different types of dye which were methylene blue (MB) and acid orange 7 (AO7) have been selected as cationic and anionic dye, respectively in this study. The selection of MB and AO7 as model dyes was due to the fact that $\mathrm{MB}$ and $\mathrm{AO} 7$ are extensively used in diverse industries and their strong affinity towards solid substrates. In addition, the presences of $\mathrm{MB}$ and $\mathrm{AO} 7$ in water bodies resulted in the negative effects towards human being and natural environment [7].

\section{METHODOLOGY}

\section{Materials}

Sugarcane bagasse was collected from nearby market and pretreated according to the method described by previous study [8]. Sugarcane bagasse was initially sundried for 10 hours per day for a 
week to remove the moisture content. The pith fragments and fibers were crushed into tiny parts and then oven dried at $90{ }^{\circ} \mathrm{C}$ for 24 hours until a constant weight was achieved. The SB was ground into fine powder using stainless steel blender (model MX-337-RF, Panasonic, Malaysia) and subsequently sieved to a constant size ranging from 100 to 200 meshes using American Society for Testing and Materials (ASTM) sieve (model PRADA, Saintifik Jaya, Malaysia). The collected sugarcane bagasse fragment was washed with distilled water under constant stirring at $70{ }^{\circ} \mathrm{C}$ until the filtrate was free of colour and turbidity. The washed sugarcane bagasse was washed again with $95 \%$ ethanol in order to eliminate the residual sugar and subsequently oven dried at $90{ }^{\circ} \mathrm{C}$ for 24 hours. Finally, sugarcane bagasse was washed again with hexane:ethanol (1:1) using Soxhlet apparatus for 4 hours to eliminate the extracted extractives and lignin. The washed sugarcane bagasse was dried at $90{ }^{\circ} \mathrm{C}$ for 24 hours. The dried sugarcane bagasse was stored in airtight plastic container at room temperature. The prepared sugarcane bagasse was abbreviated as SB.

For the application of SB and its modified form, the used MB and $\mathrm{AO} 7$ are classified as cationic and anionic dye, respectively. Whereas, $E$. coli is a gram negative bacterium while $S$. aureus and E. faecalis are gram positive bacteria.

\section{Preparation of surfactant modified SB}

Pre-treated SB was modified with three concentrations of HDTMA-Br $(0.1,1.0$ and $4.0 \mathrm{mM})$. Accurately $100 \mathrm{mg}$ of SB was weighed and placed into $100 \mathrm{~mL}$ of HDTMA-Br solution. The suspension was stirred under constant stirring at $200 \mathrm{rpm}$ for 15 minutes. The mixed solution was separated by single filtration and the filtrate was dried at $90{ }^{\circ} \mathrm{C}$ overnight. The filtrate was kept for determination of HDTMA-Br that adsorbed onto SB. The modified SB was abbreviated as SBH0.1, SBH1.0 and SBH4.0 for SB modified using HDTMA-Br with $0.1,1.0$ and $4.0 \mathrm{mM}$, respectively.

\section{Determination of surfactant adsorbed}

The determination of surfactant adsorbed onto SB was performed as described by previous literature [9]. Initially, $25 \mathrm{~mL}$ of distilled water, $5 \mathrm{~mL}$ of $2 \mathrm{M}$ sulphuric acid, $10 \mathrm{~mL}$ of chloroform and $2 \mathrm{~mL}$ of $1 \mathrm{mM}$ acid orange 7 were mixed and well-shaken in separating funnel. Then, $1 \mathrm{~mL}$ of HDTMA-Br filtrate was added to the previous mixture and the mixture was continued to be shaken vigorously. The chloroform layer was extracted and analyzed using visible spectrophotometer (model NANOCOLOR ${ }^{\circledR}$, Macherey Nagel, German) at $\lambda_{487 \mathrm{~nm}}$. The amount of HDTMA-Br adsorbed onto SB, qads $(\mathrm{mmol} / \mathrm{kg})$ was calculated as follow:

$$
q_{a d s}=\frac{\left(q_{i}-q_{e}\right) V}{w}
$$

where $\mathrm{q}_{\mathrm{i}}$ and $\mathrm{q}_{\mathrm{e}}(\mathrm{mmol} / \mathrm{L})$ are concentrations of HDTMA-Br before and after modification, respectively, $\mathrm{V}(\mathrm{L})$ is volume of HDTMA-Br solution and $\mathrm{w}(\mathrm{kg})$ is weight of SB.

\section{Characterization of SB and SBH}

The samples of SB and SBH were characterized using Fourier Transform Infrared (FTIR) spectroscopy that equipped with attenuated total reflectance (ATR) technique. The FTIR spectra were recorded using OMNIC software at spectral range of $400-4000 \mathrm{~cm}^{-1}$.

The samples of SB and SBH4.0 before and after adsorption of MB and AO7 were characterized using SEM (model Phenom Pro Generation 5, Phenom-World, Netherlands) at electron acceleration voltage of 5 and $10 \mathrm{kV}$. Prior to scanning, raw SB together with MB and AO7 loaded SB and SBH4.0 were coated with thin layer of gold using autofine coater to make samples electrically conductive.

\section{Adsorption study}

The adsorption of $\mathrm{MB}$ and $\mathrm{AO} 7$ were conducted at different concentrations of $\mathrm{MB}$ and $\mathrm{AO} 7$ which were 100, 200 and $400 \mathrm{mg} / \mathrm{L}$. The $\mathrm{MB}$ and $\mathrm{AO} 7$ stock solutions were prepared by dissolving 1000 $\mathrm{mg}$ of respected dye in $1000 \mathrm{~mL}$ of distilled water. The subsequent working solution was prepared by diluting the stock solution with distilled water to desired concentration. The batch adsorption study was performed at room temperature where $100 \mathrm{mg}$ of SB and SBH was added to $20 \mathrm{~mL}$ of $\mathrm{MB}$ and $\mathrm{AO} 7$ solution and was shaken at $200 \mathrm{rpm}$ for 2 hours. The concentration of $\mathrm{MB}$ and $\mathrm{AO} 7$ before and after adsorption was determined using visible spectrophotometer (model NANOCOLOR ${ }^{\circledR}$, Macherey Nagel, German) at $\lambda_{661 \mathrm{~nm}}$ and $\lambda_{487 \mathrm{~nm}}$, respectively. $\mathrm{MB}$ and $\mathrm{AO} 7$ adsorptions at equilibrium, $\mathrm{q}_{\mathrm{e}}(\mathrm{mg} / \mathrm{g})$ were calculated as follow:

$$
q_{e}=\frac{\left(C_{i}-C_{e}\right) V}{w}
$$

where $\mathrm{C}_{\mathrm{i}}$ and $\mathrm{C}_{\mathrm{e}}(\mathrm{mg} / \mathrm{L})$ are concentrations of $\mathrm{MB}$ and $\mathrm{AO} 7$ at initial and equilibrium, respectivel,. $\mathrm{V}(\mathrm{L})$ is volume of $\mathrm{MB}$ and $\mathrm{AO} 7$ solutions and $\mathrm{w}(\mathrm{g})$ is weight of SB and $\mathrm{SBH}$.

\section{Simultaneous action of dye adsorption and antibacterial activity}

The simultaneous action of dye adsorption and antibacterial activity involved the adsorption of $\mathrm{MB}$ and $\mathrm{AO} 7$ by $\mathrm{SB}$ and $\mathrm{SBH}$ and antibacterial activity of SB and SBH and against three different types of ATCC bacterial namely E. coli ATCC 11229, S. aureus ATCC 6538 and E. faecalis ATCC 2921 [10]. The prepared pellet of corresponding bacteria was mixed with $50 \mathrm{~mL}$ of $10 \mathrm{mg} / \mathrm{L}$ dye solution and the mixture was subsequently vortex to suspend the available bacteria. Accurately, $100 \mathrm{mg}$ of SB and SBH were weighed and added into the previous mixture. The mixture was incubated at $27{ }^{\circ} \mathrm{C}$ and shaken at $200 \mathrm{rpm}$ for 30 minutes. The incubated mixture was filtered to separate dye solution and bacteria culture. The concentration of MB and AO7 was determined as previously described in Section 2.5. The viabilities of bacteria presented after 30 minutes of incubation time with SB and SBH were determined by drop plate (DP) method. The serial dilution of bacteria culture was diluted until eight times dilution factor. Accurately, $10 \mu \mathrm{L}$ of bacteria suspension was incubated at $37^{\circ} \mathrm{C}$ for 18 hours. The bacteria colony number (CFU) available on NA plate after incubation period was counted.

\section{RESULTS AND DISCUSSIONS}

\section{Amount of Surfactant Adsorbed}

The modification of SB by HDTMA-Br was performed by using three concentrations of HDTMA-Br which were $0.1,1.0$ and $4.0 \mathrm{mM}$. The amounts of HDTMA-Br adsorbed onto SB at different initial concentrations of HDTMA-Br solution was presented in Fig. 1. As shown in Fig. 1, the amount of HDTMA-Br adsorbed onto SB was increased as the initial concentration of HDTMA-Br solution was increased. The obtained result could be explained by the presence of cellulose, hemicelluloses and lignin in SB that resulted in the formation of negatively charged external surface area of SB [11]. The negatively charged surface of $\mathrm{SB}$ could easily attract cationic surfactant HDTMA-Br, enabling more HDTMA-Br to be adsorbed onto SB. The different concentrations of HDTMA-Br that have been applied onto SB could instigate the different capacities of surfactant 
bilayer form on the surface of corresponding adsorbent. From the obtained result, it was expected that HDTMA-Br was successfully introduced into the structure of SB.

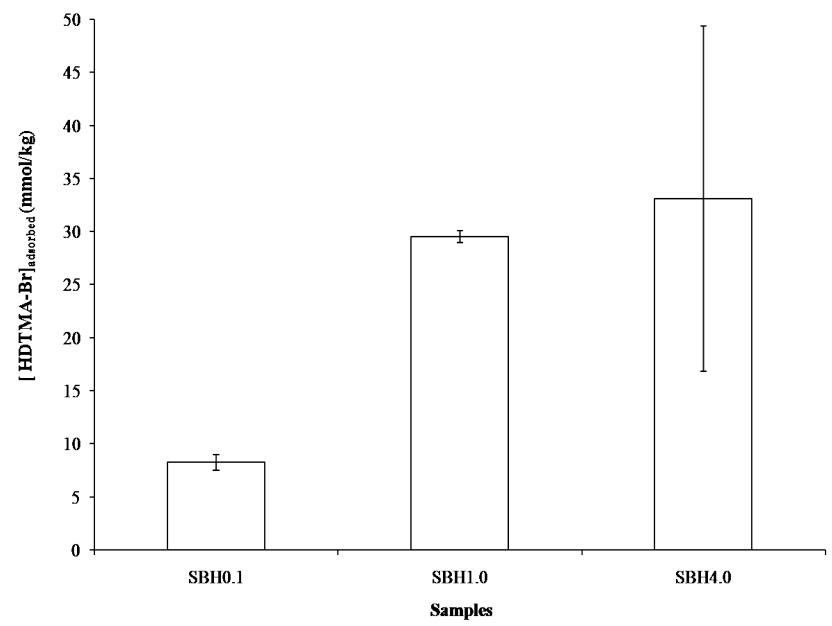

Fig. 1 Amount of HDTMA-Br adsorbed onto SB at different initial concentrations of HDTMA-Br.

\section{Characterization of SB and SBH}

The FTIR spectroscopy was performed to determine the functional groups of SB and SBH. The FTIR spectra of SB and SBH were presented in Fig. 2. As shown in Fig. 2, the strong broad peaks ranging from 3342 to $3449 \mathrm{~cm}^{-1}$ were observed for all samples that indicated to hydrogen bond vibration in $-\mathrm{OH}$ functional group of cellulose and lignin $[12,13]$. The bands in the range of 2921 to $2899 \mathrm{~cm}^{-1}$ were indicated to the existence of methyl stretching vibration from $\mathrm{CH}_{2}$ functional group of cellulose and hemicelluloses [14]. The increment in intensity of $-\mathrm{CH}$ vibration from SB to SBH4.0, as shown in Fig. 2 could influenced by the increase of aliphatic carbon content in SB in which these observed bands were indicated for the attachment of HDTMA-Br molecule onto the surface of SB [15]. The sharp intense bands in the range of 1728 to $1730 \mathrm{~cm}^{-1}$ for all samples were corresponded to $\mathrm{C}=\mathrm{O}$ stretching vibration in acetyl or ester groups of hemicelluloses and ester linkage in lignin [16, 17]. The weak peaks around $1631 \mathrm{~cm}^{-1}$ were corresponded to $\mathrm{C}-\mathrm{O}-\mathrm{O}$ bond of lignin aromatic structure [18]. The observed peaks at $1425 \mathrm{~cm}^{-1}$ for SB and $\mathrm{SBH}$ is were due to $-\mathrm{CH}_{2}$ deformation of methyl and methylene group of lignin and cellulose, respectively, as well as benzene ring in lignin structure [17]. The presence of bands at $1240 \mathrm{~cm}^{-1}$ was represented for $\mathrm{C}-\mathrm{O}-\mathrm{C}$ of cellulose chain. The peaks at $1161 \mathrm{~cm}^{-1}$ were in connection with asymmetric deformation of $\mathrm{C}-\mathrm{O}-\mathrm{O}$ in cellulose and hemicelluloses [19]. The overall FTIR spectra revealed the diverse, important chemical groups of cellulose, hemicelluloses and lignin in $\mathrm{SB}$, proving the lignocellulosic components might involve in the adsorption of HDTMA-Br onto the surface of SB. In conclusion, the result from FTIR spectra demonstrated that the treatment procedure did not change the structure of SB substantially.

SEM analysis was performed to study the surface morphology of sugarcane bagasse before surfactant modification, after surfactant modification and after adsorption of $\mathrm{MB}$ and $\mathrm{AO} 7$ [11]. The SEM micrographs of raw SB, MB and AO7 loaded SB and SBH4.0 were presented in Fig. 3. From Fig. 3(a), it was observed that SB exhibited heterogeneous surface with some porous structure. The presence of pores could provide larger surface area that facilitated the adsorption of HDTMA-Br, MB and AO7 onto SB [11]. In addition, particles of various sizes and shapes were are also observed on the outer surface of SB. These particles might be related to the cellulosic material contained in SBH $[20,21]$. However, from Fig. 3(b), it was clearly observed that the surface of SBH4.0 is was only covered with layers of smooth textures, indicating the successful adsorption of HDTMA-Br onto SB after modification with $4.0 \mathrm{mM}$ of the respected surfactant. The similar result was also reported for modification of tea waste with cetyltrimethylammonium bromide [22]. From Fig. 3 (c), (d), (e) and (f), the layer of flake shape texture was observed to be presented on the outer surfaces of SB and SBH4.0 after adsorption process, suggesting that $\mathrm{MB}$ and $\mathrm{AO} 7$ were attached on surfaces of SB and SBH4.0 after completion of adsorption reaction.

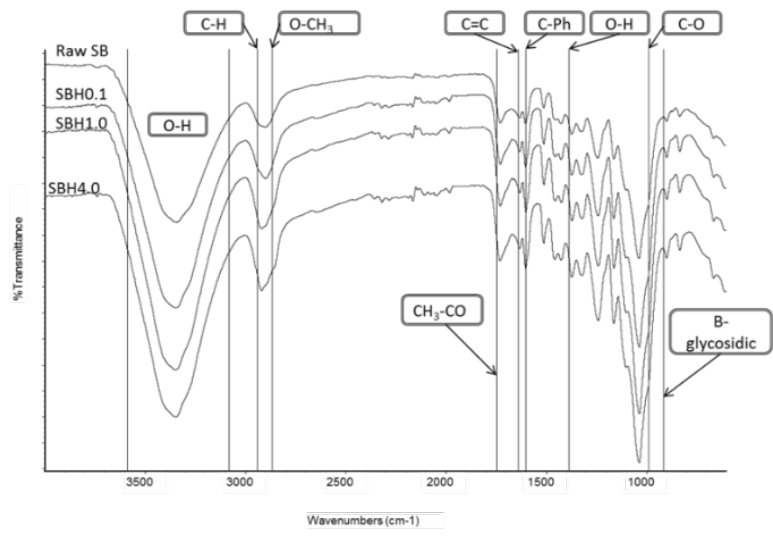

Fig. 2 FTIR spectra of SB and SBH.
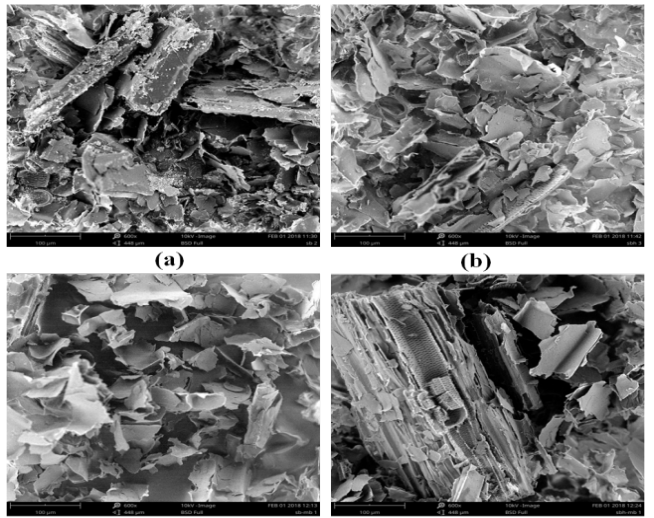

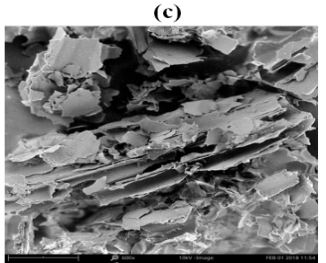

(e)

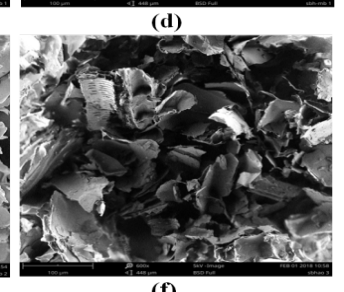

(f)
Fig. 3 SEM micrograph of (a) SB (b) SBH4.0 (c) SB after adsorption of $\mathrm{MB}$ (d) SBH4.0 after adsorption of MB (e) SB after adsorption of AO7 (f) $\mathrm{SBH} 4.0$ after adsorption of $\mathrm{AO} 7$ at $600 \mathrm{x}$ magnification.

\section{Adsorption of dye by SB and SBH}

The preliminary study on adsorptions of cationic and anionic dye was performed in order to determine the adsorption affinities of SB and SBH towards different classes of dye. The adsorption capacities of $\mathrm{SB}$ and $\mathrm{SBH}$ against $\mathrm{MB}$ and $\mathrm{AO} 7$ were presented in Fig. 3 and 4, 
respectively. As observed from Fig. 3, SB and SBH 1.0 demonstrated highest and lowest adsorption capacity towards $\mathrm{MB}$, respectively. The adsorption of MB by SB and SBH followed the trend of SB $>$ SBH4.0 $>$ SBH0.1 > SBH1.0. The amounts of MB adsorbed by SB and SBH were increased in accordance with the increase in initial concentrations of corresponding dye solutions *. In aqueous solution, hydrogen ions were released by hydroxyl groups of cellulose and lignin, which resulted in the formation of negatively charged surface area. Thus, SB was prone to attract cationic MB dye. From Fig. 4, SBH4.0 and SB showed highest and lowest adsorption of AO7, respectively. Hence, the adsorptions of $\mathrm{AO} 7$ by $\mathrm{SB}$ and $\mathrm{SBH}$ were followed the trend of SBH4.0 $>$ SBH1.0 $>$ SBH0.1 $>$ SB. The amounts of AO7 adsorbed by $\mathrm{SB}$ and $\mathrm{SBH}$ were inclined as initial concentration of $\mathrm{AO} 7$ was increased $*$.The reversal of surface charge from negative to positive potential was resulted from the surfactant modification that induced the formation of HDTMA-Br bilayer on the external surface of SB. Therefore, SBH would attract anionic AO7 dye. The outcome from current section could demonstrate the different adsorption behaviors of $\mathrm{SB}$ and $\mathrm{SBH}$ towards cationic $\mathrm{MB}$ and anionic $\mathrm{AO} 7$. The overall result from this study showed that the surfactant modification reaction might significantly influence the adsorption capacity and affinity of SB towards different classes of dye. The reversal of surface charge from negative to positive potential was resulted from the surfactant modification that induced the formation of HDTMA-Br bilayer on the external surface of SB. Therefore, SBH would attract anionic AO7 dye. The different concentrations of HDTMA-Br applied to modify SB caused different adsorption behaviors towards cationic and anionic dyes.

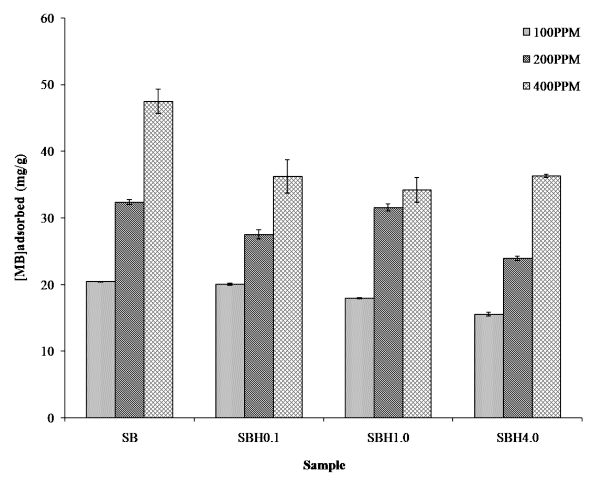

Fig. 4 Adsorption of MB by SB and SBH at different initial concentration of MB.

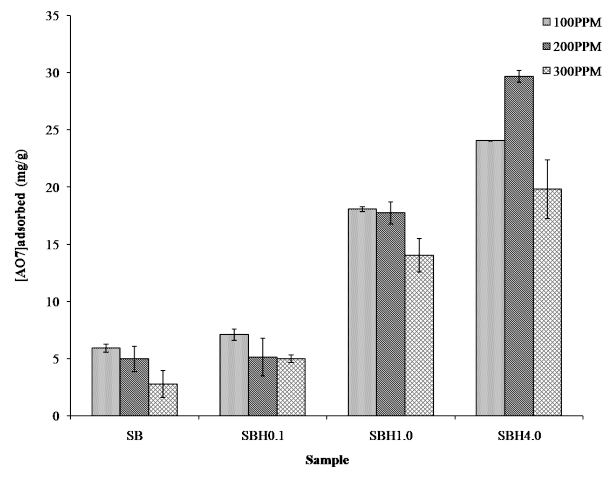

Fig. 5 Adsorption of $\mathrm{AO} 7$ by $\mathrm{SB}$ and $\mathrm{SBH}$ at different initial concentration of $\mathrm{AO} 7$.

\section{Simultaneous action of dyes adsorption and antibacterial activity of SB and SBH}

The simultaneous action of dye adsorption and antibacterial activity of SB and SBH were involved the adsorption of MB and AO7 and antibacterial activity against three different types of bacteria which were $E$. coli, $S$. aureus and $E$. faecalis by the aforementioned samples. The amount of dye adsorbed and the number of viable bacteria colony in the dye solution after the reaction were measured simultaneously The adsorption percentage of $\mathrm{MB}$ and $\mathrm{AO} 7$ and number of E. coli, $S$. aureus and E. faecalis viable colony after tested with SB and SBH were presented in Fig. 5, 6 and 7, respectively.

From Fig. 5, 6 and 7, SBH4.0 demonstrated the highest adsorption capacity towards $\mathrm{MB}$ and $\mathrm{AO} 7$ in the solution containing mixture of dye and bacteria culture. The obtained result might be influenced by the formation of HDTMA-Br bilayer on the outer surface of SBH4.0 after the modification reaction. The surfactant modification would increase the density of active functional groups on SBH4.0 that responsible for adsorption of $\mathrm{MB}$ and $\mathrm{AO}$. The incline in number of functional groups could enhance electrostatic interaction between positively charged SBH4.0 and negatively charged AO7 [19], resulting in the increment of AO7 adsorption by SBH as obtained in Fig 5, 6, 7 and 8 . In addition, the presence of bacteria culture in the dye solution might serve as an additional adsorbent for the uptake of $\mathrm{MB}$ and $\mathrm{AO} 7$ molecules. The bacteria would act as an intermediate for adsorption of $\mathrm{MB}$ and $\mathrm{AO} 7$ onto SBH4.0 [23]. The properties of bacteria as adsorbent would enhance the adsorption of MB by positively charged SBH4.0.

From Fig. 6, 7 and 8, it was observed that SB and SBH4.0 demonstrated lowest and highest antibacterial activities against $E$. coli, $S$. aureus and E. faecalis culture, respectively. The antibacterial activities of SB and SBH4.0 were followed the order of SBH4.0 > SBH1.0 > SBH0.1 > SB. As the concentrations of HDTMA-Br solution applied to modify SB were increased, the antibacterial activities of SB were also increased. These obtained results indicated that HDTMA-Br molecules might serve as an antibacterial agent and was capable of to be immobilized on the surface of SB as a carrier system [24]. The HDTMA-Br molecules were able to disrupt the cell membrane structure and indirectly inhibited the growth of E. coli, $S$. aureus and E. faecalis [25]. In general, SBH has the ability to kill both gram positive and negative bacteria. However, from Fig. 6, 7 and 8, SBH exhibited the highest antibacterial activity against gram negative in comparison to gram positive bacteria. This finding might is be due to the low thickness of peptidoglycan layer presented in E. coli cell wall relative to $S$. aureus and E. faecalis [26]. The peptidoglycan layer is essential to support the structure and survival of bacteria in various living conditions [27]. Since the peptidoglycan layer of gram positive bacteria was is thicker in comparison to gram negative bacteria, therefore, the higher capacity to kill $E$. coli was demonstrated by both $\mathrm{SB}$ and SBH in comparison to $S$. aureus and E. faecalis.

The gained results on simultaneous action of dye adsorption and antibacterial activity study showed that the modification of SB using HDTMA-Br could enhance the adsorption capacity of SB towards MB and $\mathrm{AO}$, as well as the antibacterial activity against E. coli, S. aureus and $E$. faecalis. As the initial concentration of HDTMA-Br solution used to modify the surface of SB was increased, the simultaneous action of SBH to adsorb dye and kill bacteria was increased accordingly. Therefore, it was proven that the modification of SB by cationic surfactant, HDTMA-Br was able to enhance the capability of raw sugarcane bagasse as adsorbent and antibacterial agent. 


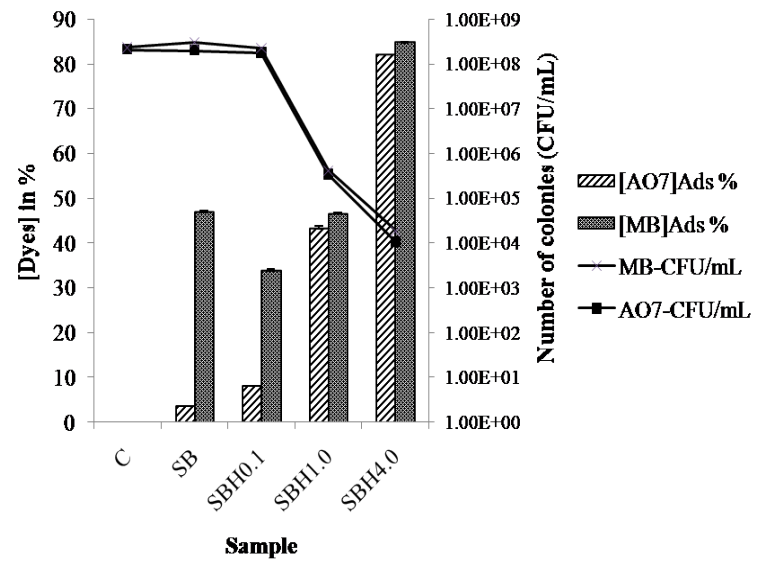

Fig. 6 Simultaneous action of $\mathrm{MB}$ and $\mathrm{AO} 7$ adsorption and number of E.coli viable after treated by SB and $\mathrm{SBH} 4.0$.

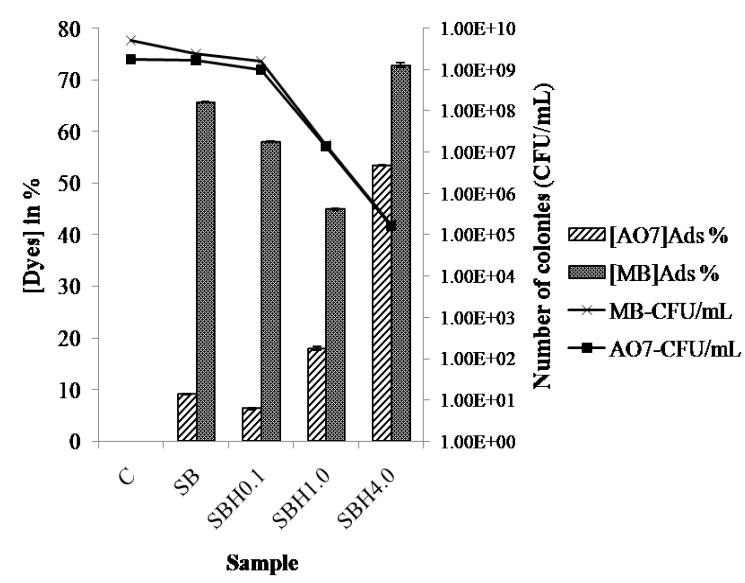

Fig. 7 Simultaneous action of MB and $A O 7$ adsorption and number of $S$. aureus viable after treated by SB and SBH4.0.

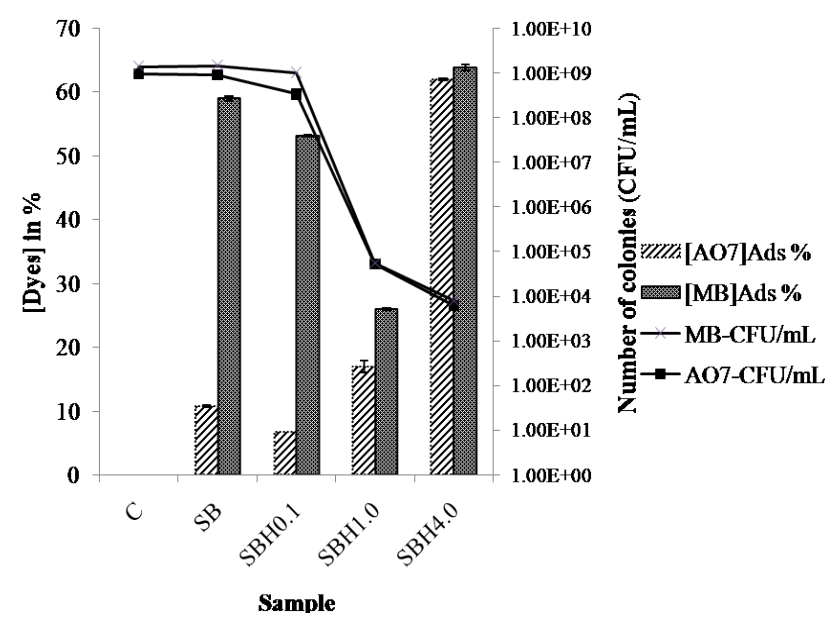

Fig. 8 Simultaneous action of $\mathrm{MB}$ and $\mathrm{AO} 7$ adsorption and number of $E$. faecalis viable after treated by SB and $\mathrm{SBH} 4.0$.

\section{CONCLUSION}

The simultaneous action of cationic and anionic dye adsorption and antibacterial activity of surfactant modified sugarcane against gram positive and gram negative bacteria was investigated. The FTIR spectra demonstrated that the chemical properties of surgarcane bagasse were unchanged after surfactant modification reaction. In addition, the increase in the aliphatic carbon content in SBH after surfactant modification process indicated that HDTMA-Br molecules were successfully adsorbed on the outer surface of raw sugarcane bagasse. The determination on the adsorbed surfactant revealed that the amount of HDTMA-Br attached onto sugarcane bagasse was increased as the initial concentration of HDTMA-Br solution was increased. The characterizations of SB and SBH further confirmed that HDTMA-Br was successfully introduced into the structure of sugarcane bagasse. The outcome from adsorption study indicated that SB and SBH4.0 exhibited highest and lowest adsorption towards methylene blue and acid orange 7, respectively. The adsorption of $\mathrm{MB}$ followed the order of $\mathrm{SB}>\mathrm{SBH} 0.1>\mathrm{SBH} 1.0>\mathrm{SBH} 4.0$ while the removal of AO7 followed the trend of SBH4.0 > SBH1.0 > SBH0.1 > $\mathrm{SB}$. The outcome from simultaneous action of dye adsorption and antibacterial activity revealed that SBH4.0 demonstrated highest uptake capacity against methylene blue and acid orange 7 , as well as largest antibacterial activity against E.coli, S.aureus and E. faecalis. However, both SB and SBH4.0 only demonstrated higher capacity to kill E. coli in comparison to $S$. aureus and E. faecalis. Therefore, it could be concluded that SB and SBH exhibited highest antibacterial activity against gram negative in comparison to gram positive bacteria. Hence, sugarcane bagasse modified with quaternary ammonium cationic surfactant, HDTMA-Br was proven to be functioned as alternative adsorbent and antibacterial agent for treatment of wastewater effluent.

\section{REFERENCES}

[1] Júnior, O. K., Gurgel, L. V. A., De Freitas, R. P., Gil, L. F. 2009. Adsorption of $\mathrm{Cu}(\mathrm{II}), \mathrm{Cd}(\mathrm{II})$, and $\mathrm{Pb}(\mathrm{II})$ from aqueous single metal solutions by mercerized cellulose and mercerized sugarcane bagasse chemically modified with EDTA dianhydride (EDTAD). Carbohydrate Polymers. 77(3): 643-650.

[2] Ministry of Agricultural and Agro-Based Industry Malaysia. 2014 Agrofood Statistics 2014. Putrajaya, Malaysia, ISSN 2232-0407.

[3] Azhar, S., Suhardy, S. D., Kasim, F. H., Saleh, M. N. 2007. Isolation and characterization of pulp from sugarcane bagasse and rice straw. Journal of Nuclear and Related Technology. 4: 109-114.

[4] Malek, N. A. N. N., Sihat, N. A., Khalifa, M. A. S., Kamaru, A. A., Jani, N. S. A., Sani, N. S. 2014. Adsorption of acid orange 7 by cetylpyridinium bromide modified sugarcane bagasse. Journal of Technology. 78(1-2): 97-103.

[5] Sharma, P., Kaur, H. 2011. Sugarcane bagasse for the removal of erythrosin B and methylene blue from aqueous waste. Applied Water Science. 1: 135-145.

[6] Zweifel, U. L., Norrman, B., Hagstrom, A. 1993. Consumption of dissolved organic carbon by marine bacteria and demand for inorganic nutrients. Marine Ecology-Progress Series. 101(1-2): 23-23.

[7] Özer, D., Dursun, G., Özer, A. 2007. Methylene blue adsorption from aqueous solution by dehydrated peanut hull. Journal of Hazardous Materials. 144(1): 171-179.

[8] Gusmão, K. A. G., Gurgel, L. V. A., Melo, T. M. S., Gil, L. F. 2012. Application of succinylated sugarcane bagasse as adsorbent to remove methylene blue and gentian violet from aqueous solutions-kinetic and equilibrium studies. Dyes and Pigments. 92(3): 967-974.

[9] Scott, G. V. 1968. Spectrophotometric determination of cationic surfactants with orange II. Analytical Chemistry. 40(4): 768-773. 
[10] Salim, M. M., Malek, N. A. N. N. 2016. Characterization and antibacterial activity of silver exchanged regenerated $\mathrm{NaY}$ zeolite from surfactantmodified NaY zeolite. Materials Science and Engineering: C. 59: 70-77.

[11] Kamaru, A. A., Sani, N. S., Malek, N. A. N. N. 2016. Raw and surfactantmodified pineapple leaf as adsorbent for removal of methylene blue and methyl orange from aqueous solution. Desalination and Water Treatment. 57(40): 18836-18850.

[12] Chowdhury, S., Chakraborty, S., Saha, P. 2011. Biosorption of basic green 4 from aqueous solution by Ananas comosus (pineapple) leaf powder. Colloids and Surfaces B: Biointerfaces. 84(2): 520-527.

[13] Kannan, N., Sundaram, M. M. 2001. Kinetics and mechanism of removal of methylene blue by adsorption on various carbons - a comparative study. Dyes and Pigments. 51(1): 25-40.

[14] Mulinari, D. R., Voorwald, H. J. C., Cioffi, M. O. H., Da Silva, M. L. C. P., and Luz, S. M. 2009. Preparation and properties of HDPE/sugarcane bagasse cellulose composites obtained for thermokinetic mixer. Carbohydrate Polymers. 75(2): 317-321.

[15] Namasivayam, C., Sureshkumar, M. V. 2007. Removal of sulfate from water and wastewater by surfactant-modified coir pith, an agricultural solid 'waste' by adsorption methodology. Journal of Environment Engineering and Management. 17(2): 129-135.

[16] Nayan, N. H. M., Razak, S. I. A., Rahman, W. A. W. A., Majid, R. A. 2013. Effects of mercerization on the properties of paper produced from malaysian pineapple leaf fiber. International Journal of Engineering Technolology. 13(4), 1-6.

[17] Maniruzzaman, M., Rahman, M. A., Gafur, M. A., Fabritius, H., Raabe, D. 2012. Modification of pineapple leaf fibers and graft copolymerization of acrylonitrile onto modified fibers. Journal of Composition Material. 46(1): 79-90.

[18] Weng, C. H., Wu, Y. C. 2011. Potential low-cost biosorbent for copper removal: Pineapple leaf powder. Journal of Environmental Engineering. 138(3): 286-292.
[19] Kousha, M., Daneshvar, E., Sohrabi, M. S., Jokar, M., Bhatnagar, A 2012. Adsorption of acid orange ii by raw and chemically modified brown macroalga Stoechospermum marginatum. Chemical Engineering Journal. 192: 67-76.

[20] Dezhampanah, H., Mousazadeh, A., Mousazadeh, I. 2014. Sugarcane bagasse and modified rice husk for the removal of malachite green from aqueous Wastes. European Chemical Bulletin. 3(4): 400-406.

[21] Sharma, P., Kaur, H. 2011. Sugarcane bagasse for the removal of erythrosin $\mathrm{b}$ and methylene blue from aqueous waste. Applied Water Science. 1(3-4): 135-145.

[22] Foroughi-dahr, M., Abolghasemi, H., Esmaieli, M., Nazari, G., Rasem, B. 2015. Experimental study on the adsorptive behavior of congo red in cationic surfactant-modified tea waste. Process Safety and Environmental Proection. 95: 226-236.

[23] Srinivasan, A., Viraraghavan, T. 2010. Decolorization of dye wastewaters by biosorbents: A review. Journal of Environmental Management. 91(10): 1915-1929.

[24] Zhao, Y., Chen, M., Zhao, Z., Yu, S. 2015. The antibiotic activity and mechanisms of sugarcane (Saccharum officinarum L.) bagasse extract against food-borne pathogens. Food Chemistry. 185: 112-118.

[25] Malek, N. A. N. N., Ramli, N. I. A. 2015. Characterization and antibacterial activity of cetylpyridinium bromide (CPB) immobilized on kaolinite with different CPB loadings. Applied Clay Science. 109-110: 814.

[26] Navarre, W.W., Schneewind, O. 1999. Surface proteins of gram-positive bacteria and mechanisms of their targeting to the cell wall envelope. Microbiology and Molecular Biology Reviews. 63(1): 174-229.

[27] Wiedemann, I., Breukink, E., van Kraaij, C., Kuipers, O. P., Bierbaum, G., de Kruijff, B., Sahl, H. G. 2001. Specific Binding of Nisin to the Peptidoglycan Precursor Lipid II Combines Pore Formation and Inhibition of Cell Wall Biosynthesis for Potent Antibiotic Activity. Journal of Biological Chemistry. 276(3): 1772-1779. 